\title{
COMPARING THE EFFICACY OF ENDOSEQUENCE ROOT REPAIR MATERIAL, BIODENTINE, MTA ANGELUS AS RETROGRADE FILLING IN MICROBIAL LEAKAGE BY CONFOCAL LASER SCANNING MICROSCOPE
}

\author{
Mahmoud M. Badr * and Mohammed E. Rokaya**
}

\begin{abstract}
This study aimed to compare the efficacy of EndoSequence ${ }^{\circledR}$ Root Repair Material, Biodentine, and MTA angelus ${ }^{\circledR}$ retrograde materials in microbial leakage while confirmed with Confocal Laser Scanning Microscope (CLSM).

Methods: 55 maxillary single rooted teeth were used in this study. The teeth were decoronated at $16 \mathrm{~mm}$. root canals was prepared by using ProTaper rotary Ni-Ti instruments. Obturation of the root canals was performed using a single-cone Pro-taper F3 size Gutta-percha along with the sealer (AH+ plus). The apical $3 \mathrm{~mm}$ of the roots were resected. Root end cavity was prepared by ultrasonic retro-tips. Samples were divided into 5 groups with 11 samples each according to retrograde cavities filling. Group 1 (EndoSequence), Group 2 (Biodentine). Group 3 (MTA angelus), Group 4 (Positive control), and Group 5 (Negative control). Dual chamber apparatus was prepared to test the retrograde filling leakage. The E.F in CLSM with magnification of $20 \mathrm{X}$ to measures of E. Faecalis penetration depth through retrograde materials.
\end{abstract}

Results: EndoSequence ${ }^{\circledR}$ had superior outcome in microbial leakage along with penetration depth into the dentinal tubules with statistically significant difference when compared to Biodentine $^{\mathrm{TM}}$ and MTA angelus ${ }^{\circledR}(\mathrm{p} \leq 0.05)$. On other hand there was no any statistically significant difference between Biodentine ${ }^{\mathrm{TM}}$ and MTA angelus ${ }^{\circledR}(\mathrm{p}>0.05)$ with more leakage in dual chamber whereas bacterial penetration into the dentinal tubules in CLSM was measured.

Conclusions: EndoSequence showed better results in both bacterial leakage and in bacterial penetration.

* Lecturer of Endodontics, Faculty of Oral and Dental Medicine, Future University, Egypt.

** Associate Professor of Endodontics, Faculty of Dental Medicine, Al-Azhar University, Assuit, Egypt. 


\section{INTRODUCTION}

Apical surgery is done to management of teeth with a periapical lesion that cannot be overcome with a conventional endodontic treatment. This line of treatment is done to maintain a tooth with significant periapical lesion that cannot be treated with ordinary method $^{(1)}$.

Apicoectomy with retrograde filling is a well-known alternative in endodontics in case of orthograde endodontic therapy failure ${ }^{(2)}$. The root-end filling material should be compacted into the cavity with a small plugger to ensure a dense fill. The objective of retrograde filling is to select a material that can produce a good seal that prevents any irritants from entering inside the root and entering the periradicular tissues. For root-end filling, a variety of materials have been propagated in the past for the root end filling ${ }^{(3)}$.

A variety of materials used as amalgam, guttapercha, IRM, GIC, bonding agents, but microleakage is still evident with these materials. Recently newer materials have used as Biodentin, Bioceramic, and MTA which showed less microleakage ${ }^{(4)}$.

Mineral trioxide aggregate was the first member of the calcium silicate family to be intro-duced ${ }^{(5)}$. Another promising biocompatible root-end material is Biodentine ${ }^{\mathrm{TM}}$. Is nontoxic material with a tricalcium silicate core, which has superior handling properties to MTA, and exhibits similar biocompatibility. EndoSequence endodontic repair materials introduced to the market. The materials have recommended for perforation repair, apical surgery, apical plug, and pulp capping ${ }^{(6)}$.

CLSM can measure both life or dead bacteria and provides data about the existence and dissemination of microorganisms within the root dentine ${ }^{(7)}$.

So, the present study was designed to evaluate the efficiency of EndoSequence ${ }^{\circledR}$, Biodentine ${ }^{\mathrm{TM}}$,
M.T.A angelus ${ }^{\circledR}$ as retrograde obturating materials in microbial leakage and being confirmed with CLSM.

\section{MATERIALS AND METHODS}

\section{Teeth selection}

55 maxillary single rooted teeth were collected from clinic of oral and maxillofacial surgery department, Al Azhar University. Only single rooted teeth with single root canal and mature apex were selected to be used in the study. A solution of $5.25 \%$ sodium hypochlorite (Egyptian Detergent Company, Egypt) soaked into gauze was used to remove any soft tissue covering the root surface and any calculus was removed by the aid of ultrasonic scaler (wood packer china). For standardization of working length of $16 \mathrm{~mm}$ fig. (1). The teeth were decoronated by using a diamond tapered stone mounted on high-speed hand piece (W\&H Burmoos, Austria) with water spray at $16 \mathrm{~mm}$. from the apex. Flattening of the coronal portion of the roots was done with wheel stone.

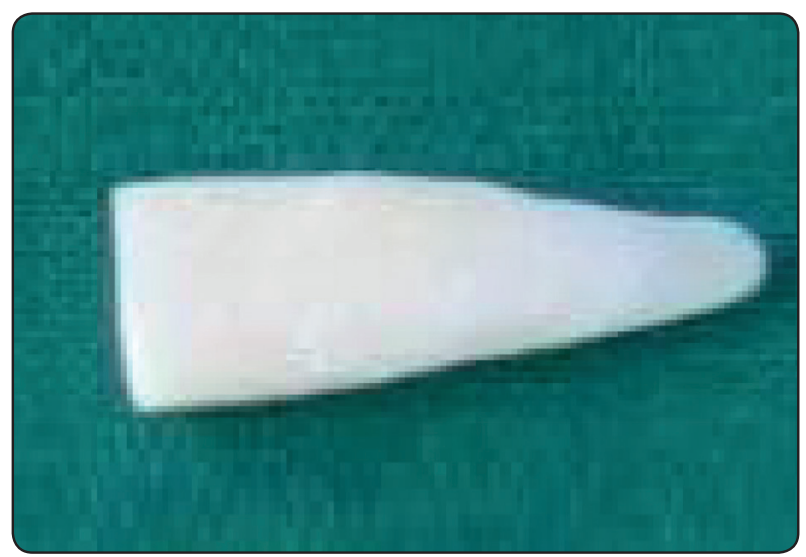

Fig. (1): A photograph showing a specimen after de-coronation.

K- File No.10 (Dentsply, Maillefer, Tulsa, OK) was introduced into the canal till the tip of the file is seen from the apex to ensured patency. The teeth were stored in normal saline solution $0.9 \%$ at room temperature till time of use. 


\section{Root canal preparation}

Chemo-mechanical preparation were performed utilizing Pro-Taper rotary Ni-Ti files* till file \#F3 in a crown-down manner with electric endodontic motor $^{* *}$ at $300 \mathrm{rpm}$. Plastic syringe with a side vented needle (SVN) was used to deliver the irrigating solution into the root canals. The irrigation protocol was done as follows; $5 \mathrm{~mL} \mathrm{NaOCl}(2.5 \%)$ for biofilm removal, EDTA(15\%) for eradication of the smear layer, then $\mathrm{NaOCl}(2.5 \%)$, then saline was used as the final flush. Afterwards, drying of the root canals were performed using sterile standardized paper points. Pro-taper gutta-percha (\#F3) and the sealer $(\mathrm{AH}+)^{* * *}$ were utilized for obturating the root canals with the single cone filling approach.

The apical $3 \mathrm{~mm}$ of the root was horizontally resected using $0.2 \mathrm{~mm}$ sharp disc. The retrograde cavity was done utilizing ultrasonic retro-tips ${ }^{* * * *}$ about $3 \mathrm{~mm}$ depth.

\section{Grouping of samples:}

Samples were divided into 5 groups with 11 samples each.:

G1: EndoSequence was used to fill the root-end cavity.

G2: BioDentine was used to fill the root-end cavity.

G3: MTA Angelus was used to fill the root-end cavity.

(With MTA carrier and condensed by plugger)

G4: Root-end cavity was left without filling (control +ve).

G5: Root-end cavity was filled with wax and double-layered nail varnish was used to coat the entire root dentine including the apical part (control -ve)
Materials were mixed according to manufacturer's instructions. In all samples, double-layered nail varnish was used to coat the entire root dentin excluding the apical part.

\section{The DUAL-CHAMBER apparatus:}

Dual chamber apparatus was prepared as described by siqueria ${ }^{(8)}$. The Ependorf tips were resected. Teeth were placed up to $5 \mathrm{~mm}$ from the apical portion. Cyano-acrylate was placed to fill the articulation in between the sample and microtube. $30 \mathrm{ml}$ of serum tubes having rubber stoppers work as the other chamber fig. (2). The dual apparatuses had been sterilized using gamma radiation (Cobalt 60 irradiator with dose rate of $1.774 \mathrm{KGY}$ with total dose of $25 \mathrm{KGY})^{(9)}$.

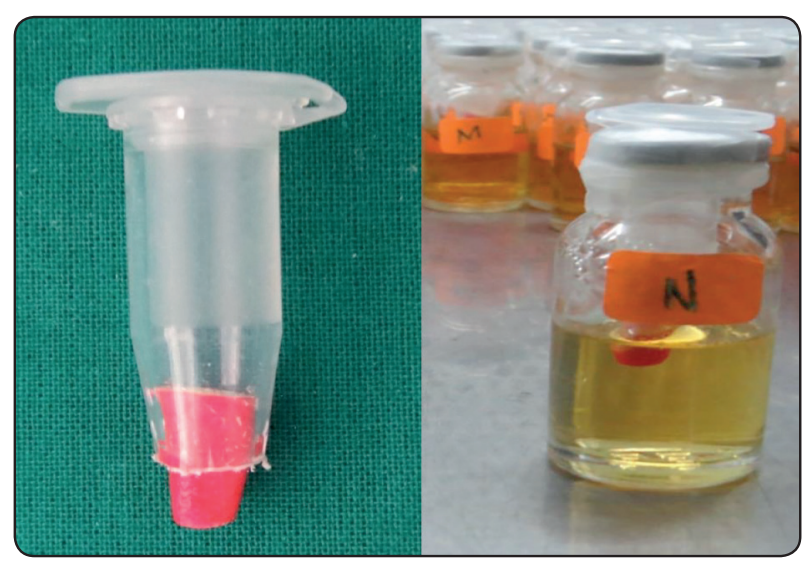

Fig. (2): A photograph showing Dual chamber model.

\section{Sterilization of the teeth:}

Samples were inserted into sterilization bags and sterilized using gamma radiation ${ }^{(9)}$.

\section{Bacterial inoculation}

The E. faecalis used in this study were prepared by growing Pure E. faecalis on a bile-esculin plate

\footnotetext{
* Dentsply Maillefer, Ballaigues, Switzerland.

** X-smart plus, Densply-Maillefer, Ballaigues, Switzerland.

*** De Trey - Dentsply, Konstanz, Germany.

**** Z2760, Gorbadius Equipment Medical-Odontology, Chile.
} 
for 24 hours at $37^{\circ} \mathrm{C}$. The microbial culture was done in BHI solution and then the incubation period was at room temperature for 1 day. According to the MacFarland scale, Resuspension of the microbes following the McFerland scale to $4 * 10^{7} \mathrm{CFU} / \mathrm{ml}$. This is followed by inoculating $6 \mu \mathrm{l}$ of microbial culture in a container for every sample placed in the tubes using pipettes every other day.

The apical portions of the roots were placed in sterile BHI broth. Then incubation of the whole apparatus at room temperature $\left(37^{\circ} \mathrm{C}\right)$ for 40 days. The Brain Heart Infusion broth was rechecked every day for turbidity. E.F Specific bacterial identification in each specimen was confirmed by the unique species-specific PCR. The density of the turbidity was scaled in ELLISA READER (BioTek, Winooski, Vermont, U.S.A) at the $40^{\text {th }}$ day in every sample.

\section{Clsm assessment:}

A $60 \mathrm{~mm}$ barrel-shaped block was fabricated in self cure acrylic repair material for every specimen and samples were immersed into it leaving the apical part exposed. Then it was resected to $30 \mu \mathrm{m}$ length horizontally at right angle to the long axis of the barrel-shaped block using a specific micro-tome fig. (3).
Every tooth was dyed with fluorescent Propidium Iodine stain for verification of the living and dead microorganisms and the quantity of the Enterococcus Faecalis (E.F) microorganisms with CLSM under 20X magnification to measures of E. Faecalis penetration depth through retrograde materials of the test groups by micrometres $(\mu \mathrm{m}) \mathrm{Fig}$. $(4,5)$.

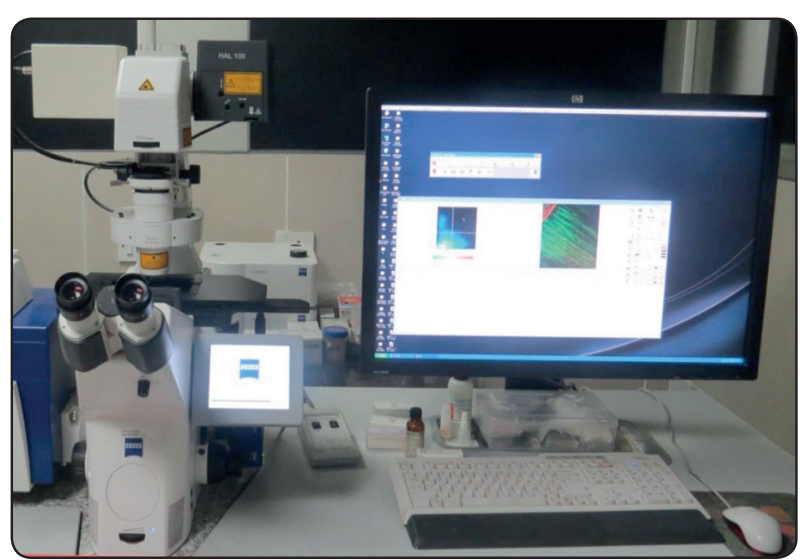

Fig. (4): A photograph showing Confocal Laser Scanning Microscope.

Mean value and standard deviation were determined, and the results were correlated by using TUKEY HSD and ANOVA with significance difference value was set at $\mathrm{p} \leq 0.05$.

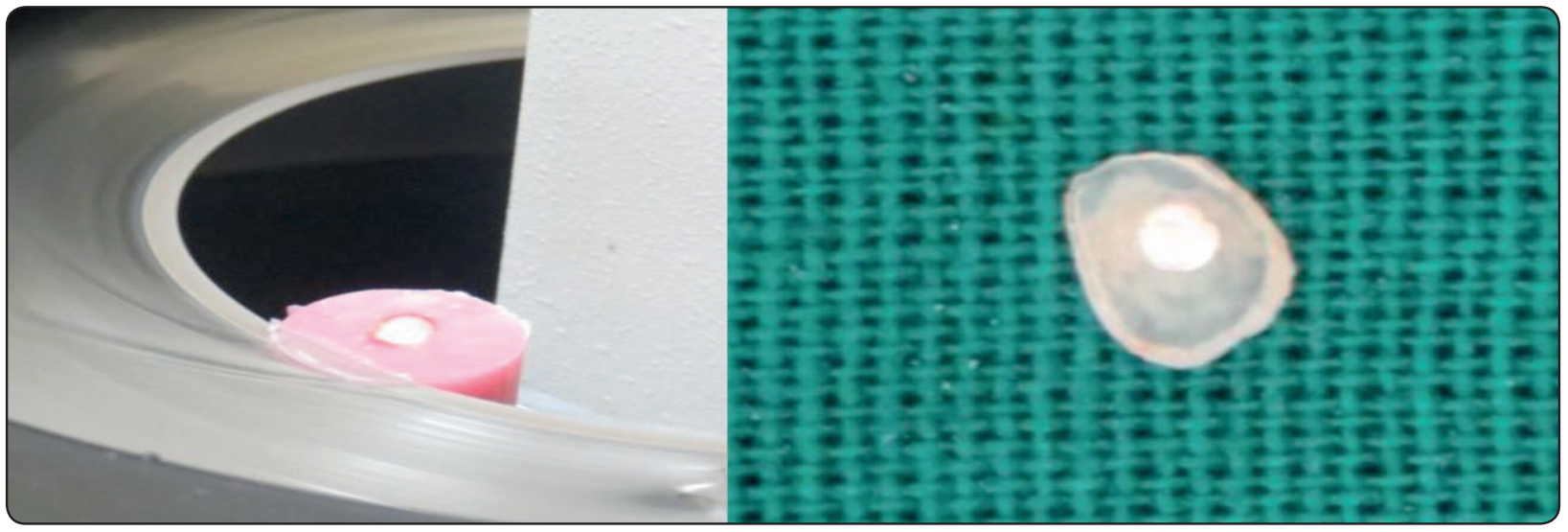

Fig. (3): A photograph showing tooth Sectioned by a micro-tome. 

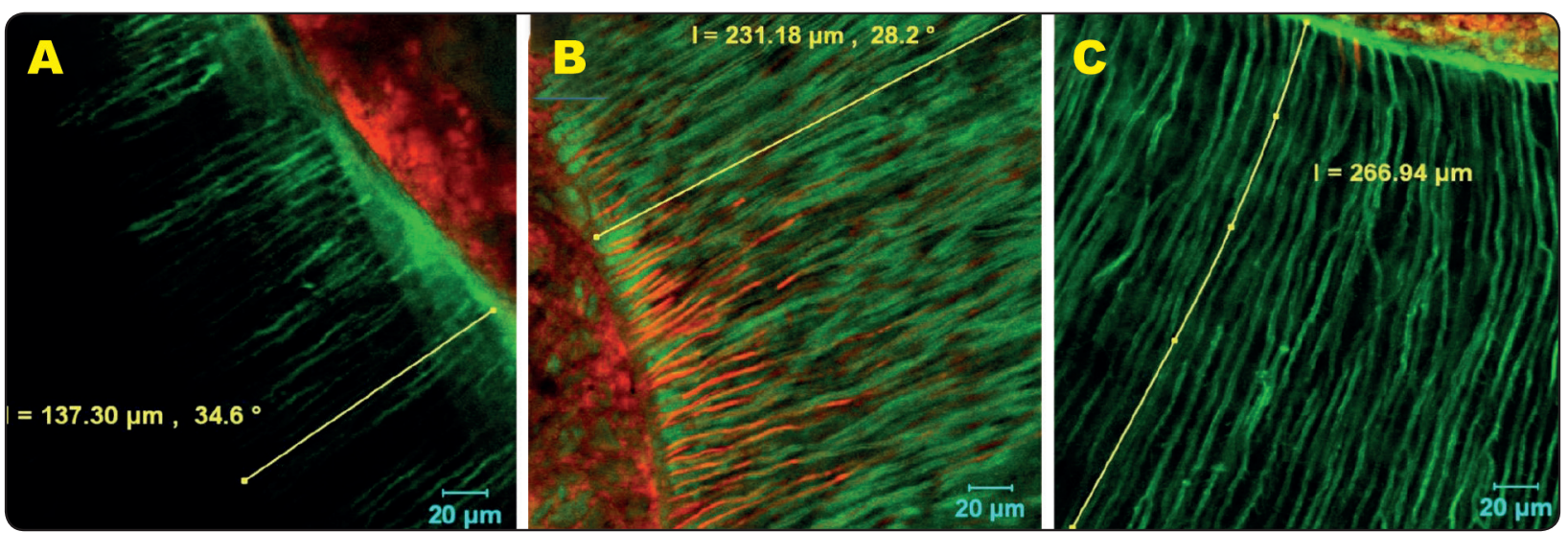

Fig. (5): A photograph showing the penetration depth of Enterococcus faecalis was measured by CLSM images at 20x of the three experimental groups (A: EndoSequence, B: Biodentine, and C: MTA angelus).

\section{RESULTS}

\section{Turbidity measurement}

The results of Turbidity measurement are listed in table (1) and illustrated in figure (6).

The results of present study showed that EndoSequence $^{\circledast}$ scored the lowest turbidity measurement $19.808 \pm 8.443$, and Biodentine ${ }^{\mathrm{TM}}$ scored 25.516 \pm 6.640 . On other hand MTA angelus ${ }^{\circledR}$ scored the highest turbidity measurement $25.725 \pm 8.753$.

These results showed that EndoSequence ${ }^{\circledR}$ had statistically significance difference in terms of

TABLE (1): The mean and standard deviation of turbidity measurement.

$\begin{array}{cccc} & \begin{array}{c}\text { The mean of turbidity } \\ \text { measurement }\end{array} & \begin{array}{c}\text { Standard } \\ \text { deviation }\end{array} & \text { P - Value } \\ \text { EndoSequence } & 19.808^{\mathrm{a}} & \pm 8.443 & \\ \text { Biodentine } & 25.516^{\mathrm{b}} & \pm 6.640 & \\ \text { MTA angelus } & 25.725^{\mathrm{b}} & \pm 8.753 & 1.00^{\mathrm{ns}} \\ \text { Positive control } & 48.19165^{\mathrm{c}} & \pm 0.795 & \\ \text { Negative control } & 00000 & 000000 & \\ \text { P - Value } & 0.04^{*} & \end{array}$

Different letters mean statistical different. *; significant $(p \leq 0.05) n s$; non-significant ( $p>0.05)$. turbidity measurement in comparison to, Biodenti$\mathrm{ne}^{\mathrm{TM}}$, and MTA angelus ${ }^{\circledR}(\mathrm{p} \leq 0.05)$. On other hand there wasn't any statistically significant difference between Biodentine ${ }^{\mathrm{TM}}$ and MTA angelus ${ }^{\circledR}$ which showed similar results $(\mathrm{p}>0.05)$.

\section{Penetration depth:}

The mean value and standard deviation of bacterial penetration of E.F through retrograde materials of the test groups by CLSM under 20X magnification in micrometres are listed in table (2) and illustrated in figure (7).

TABLE (2): The mean and standard deviation of the distribution of microbial penetration in CLSM of all the test groups.

$\begin{array}{cccc} & \begin{array}{c}\text { The mean of bacterial } \\ \text { penetration depth }\end{array} & \begin{array}{c}\text { Standard } \\ \text { deviation }\end{array} & \begin{array}{c}\text { P - } \\ \text { Value }\end{array} \\ \text { EndoSequence } & 96.89^{\mathrm{a}} & \pm 20.313 & \\ \text { Biodentine } & 120.625^{\mathrm{b}} & \pm 11.114 & 0.17^{\mathrm{ns}} \\ \text { MTA angelus }^{\circledR} & 130.185^{\mathrm{b}} & \pm 16.706 & \\ \text { P - Value } & 0.03^{*} & & \end{array}$

Different letters mean statistical different.

*; significant ( $p \leq 0.05) n s$; non-significant ( $p>0.05)$. 


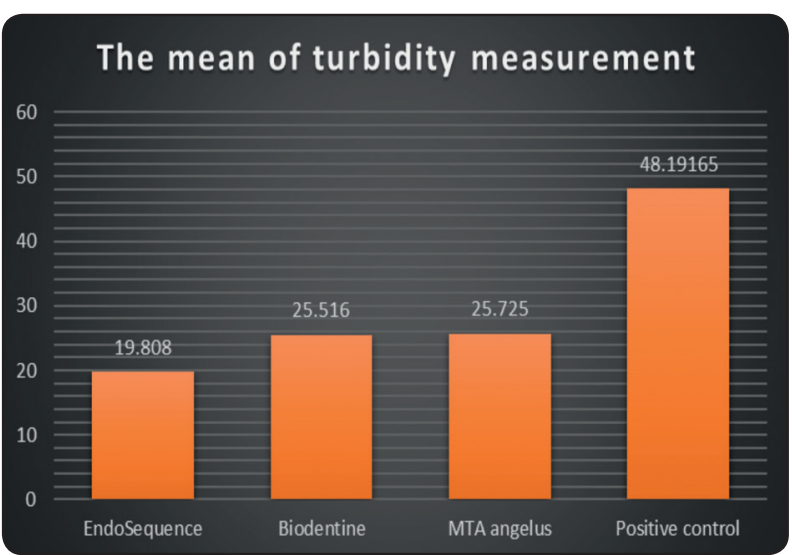

Fig. (6): A chart showing the mean of turbidity measurement of the test groups.

The results showed that the penetration depth of Enterococcus faecalis into the dentinal tubules with EndoSequence ${ }^{\circledR}$ was $96.89 \pm 20.313$, Biodentine ${ }^{\mathrm{TM}}$ $120.625 \pm 11.114$, and MTA angelus ${ }^{\circledR} 130.185 \pm 16.706$.

The bacterial leakage of E.F through the root-end obturating substances revealed that EndoSequence ${ }^{\circledR}$ had superior outcomes in terms of microbial leakage and also in the depth of penetration into dentinal tubules with statistically significance difference in comparison with Biodentine ${ }^{\mathrm{TM}}$ \&MTA angelus ${ }^{\circledR}(\mathrm{p}$ $\leq 0.05$ ). On other hand there was no any statistically significant difference between Biodentine ${ }^{\mathrm{TM}}$ \& MTA angelus ${ }^{\circledR}(p>0.05)$ and greater leakage in the dual chamber where penetration of bacteria into the dentinal tubules in Confocal Laser Scanning Microscope was measured.

\section{DISCUSSION}

The purpose for apical surgery is to preserve the tooth on the oral cavity to perform its function. This goal should be achieved by a retrograde filling ${ }^{(10)}$.

The experimental design of this study was designed to compare the efficacy of EndoSequence ${ }^{\circledR}$, Biodentine, and MTA angelus ${ }^{\circledR}$ as retrograde obturating material in terms of microbial leakage and confirmation with CLSM.

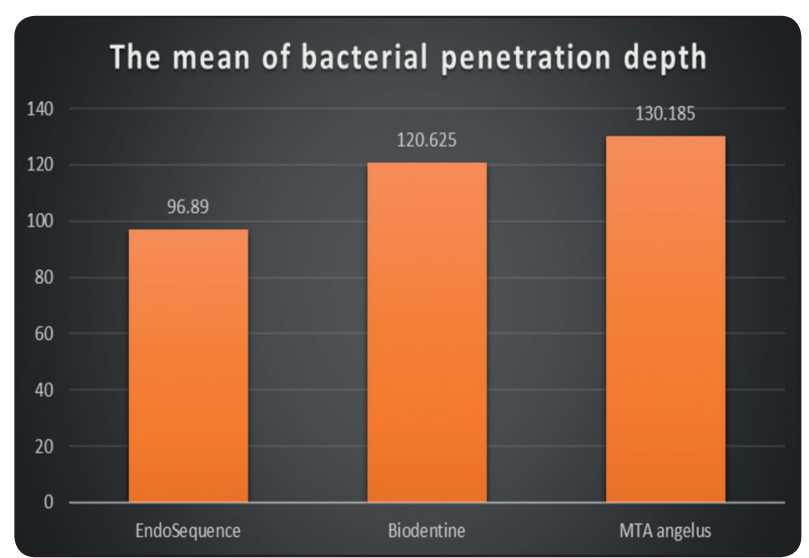

Fig. (7): A chart represents the mean value distribution of microbial penetration in CLSM through retrograde materials by $\mu \mathrm{m}$.

Other studies have revealed that microbial leakage approaches are superior in the assessment of the sealing capabilities in comparison with other techniques like microscopical, histochemical and microbiological approaches. However in the present study, microbial leakage assessment was performed with Ent. Faecalis microorganisms as the most persistent pathogen in long standing infections or cases with unsuccessful root canal treatments ${ }^{(11)}$.

Different microscopically-dependent approaches to evaluate the sealing capabilities of the retrograde obturating materials are existing like confocal laser scanning microscope (CLSM), Transmissionelectron microscope (TEM), stereo-microscope, scanning electron microscope (SEM). The Confocal Laser Scanning Microscope that was used in this study provide specific information about the living and dead microorganisms in the dentinal tubules through the dying techniques. In the present study, dual chamber method of microbial leakage was utilized, where (+ve) control and (-ve) control groups are mandatory to approve the competence of the experimental model. The control -ve specimens showed no turbidity however turbidity was shown in every control +ve specimen confirming the exact competence of the experimental model. ${ }^{(12)}$.

Moreover, the bio ceramic substances usually exhibit some expansion with the presence of 
moisture/water that is followed by shrinkage in dry conditions. However, in routine clinical situations, the retrograde obturating substances are not immerged in water, though the normally existing periapical fluids allows the expansion-shrinkage to occur ${ }^{(13)}$. In the present study, the retrograde obturating substances were submerged in BHI broth rather than water or saline.

The results of turbidity of the present study showed that: EndoSequence ${ }^{\circledR}$ had statistical significance difference in terms of turbidity measurement in comparison with Biodentine ${ }^{\mathrm{TM}}$, and MTA angelus ${ }^{\circledR}(\mathrm{p} \leq 0.05)$. On other hand there wasn't any statistically significant difference between Biodentine $^{\mathrm{TM}}$ and MTA angelus ${ }^{\circledR}$ which showed similar results $(\mathrm{p}>0.05)$.

On other hand the bacterial leakage of $E n$ terococcus $F$. via root-end obturating substances revealed that: EndoSequence ${ }^{\circledR}$ had superior outcomes in terms of microbial leakage and also in depth of penetration into the dentinal tubules with statistical significance difference in comparison with Biodentine ${ }^{\mathrm{TM}} \&$ MTA angelus ${ }^{\circledR}(\mathrm{p} \leq 0.05)$. On other hand there was not any statistically significant difference between Biodentine ${ }^{\mathrm{TM}}$ and MTA ange$\operatorname{lus}^{\circledR}(\mathrm{p}>0.05)$ with greater leakage in the dual-chamber apparatus considering that the microbial depth of penetration into the dentinal tubules in Confocal Laser Scanning Microscope was measured.

The superior sealing capability of Endosequence root repair material may be related to the presence of the tricalcium silicate particles that are bioactive and bond chemically to the hydroxy-apatite crystals of the root canal dentin ${ }^{(14)}$ and with adequate water the bio ceramic materials expand ${ }^{(13)}$. Some microcracks along with micro-structural modifications were seen in the root canal dentin at the interphase between root canal dentin and Biodentine in dry conditions that may provide access for bacterial entrance and spread $^{(15)}$.

Similar to the result of our study, Chenn et al showed that Endosequence root repair material had superior sealing capability than MTA with denoted more dentin surface layered by either bone, periodontal ligament-like tissues, or cementum-like tissues just bordering the resected root-end apical portion in a dog model. This was also confirmed by Cone Beam CT and micro-CT. The authors also observed that there were no statistically significance difference between the sealing capabilities of MTA $\&$ Biodentine ${ }^{\mathrm{TM}(16)}$.

Our study results are similar to other study that evaluated the sealing capability of different root-end repair materials like Biodentin, MTA+ and White Pro-Root MTA. The authors showed that there was no statistically significance difference within the tested materials ${ }^{(17)}$.

The findings of this study do not correlate with the results declared that Endosequence root repair material revealed comparable marginal adaptation in comparison to MTA ${ }^{(18)}$. however one other study revealed fewer marginal gap in comparison to MTA $^{(19)}$.

\section{CONCLUSIONS}

ERRM revealed superior outcomes in terms of microbial leakage and in depth of microbial penetration.

\section{REFERENCES}

1. Verma J, Ahuja V. Apicoectomy - A review. The Journal of Dental Panacea 2021;3(1):15-19.

2. Aly, Y., El Shershaby, S. \& El-Sherif, S. Bond strength and marginal adaptation of a novel root-end filling material. Bull Natl Res Cent 2020; 44:142.

3. Amira A. Moustafa; Inas T. Motawea; Rania E. Bayoumi. "Solubility and Sealing Ability of Recently Introduced Biocearmic Root-End Filling Materials". Al-Azhar Dental Journal for Girls, October 2020; 4:547-557.

4. Gupta R, Kewalramani R. In-vitro evaluation of microleakage of bioceramic root-end filling materials: A spectrophotometric study. J Oral Biol Craniofac Res. 2021;11(2):330-333. 
5. Dutta and Saunders. Calcium silicate materials in endodontics. Dent Update 2014;41: 708-722.

6. Madfa A, Al-Sanabani F, Al-Kudam N. Endodontic Repair Filling Materials: A Review Article. British Journal of Medicine and Medical Research 2014; 4(16):3059-3079.

7. Tsesis I, Elbahary S, Venezia NB, Rosen E. Bacterial colonization in the apical part of extracted human teeth following root-end resection and filling: a confocal laser scanning microscopy study. Clin Oral Invest 2017; 28:1-8.

8. Siqueira JF, Roçcas IN, Abad EC, Castro AJ, Gahyva SM, Favieri A. Ability of three root-end filling materials to prevent bacterial leakage. J Endod 2001;27(11):673-5.

9. Alkhawas M A, Abdelmonem R, Rokaya M E. Evaluation of Antibacterial Effect of a new root canal irrigating Formula of Salvadora persica Roots Nanoparticles. An In vitro Study. EDJ, 2019; 65: 787-792.

10. Von Arx T. Apical surgery: A review of current techniques and outcome. Saudi Dent J. 2011;23(1):9-15.

11. Torabinejad M, Rastegar AF, Kettering JD, Ford TR. Bacterial leakage of mineral trioxide aggregate as a rootend filling material. J Endod 1995;21(3):109-12.

12. Tsesis I, Elbahary S, Venezia NB, Rosen E. Bacterial colonization in the apical part of extracted human teeth following root-end resection and filling: a confocal laser scanning microscopy study. Clin Oral Invest 2017; 28:1-8.

13. Aziz A, Chandler NP, Hauman CH, Leichter JW, McNaughton A, Tompkins GR. Infection of apical dentin and root-end cavity disinfection. J Endod 2012; 38(10):1387-90.
14. Seedat HC, Van der Vyver PJ. An in-vitro comparison of microleakage between three calcium silicate cements and amalgam. S Afr Dent 2016;71(3):100-5.

15. Camilleri J, Grech L, Galea K, Keir D, Fenech M, Formosa L, Damidot D, Mallia B. Porosity and root dentine to material interface assessment of calcium silicate-based root-end filling materials. Clin Oral inves 2014;18(5): 1437-46.

16. Chen I, Karabucak B, Wang C, Wang HG, Koyama E, Kohli MR, Nah HD, Kim S. Healing after root-end microsurgery by using mineral trioxide aggregate and a new calcium silicate-based bio ceramic material as rootend filling materials in dogs. J Endod 2015;41(3):389-99.

17. Nanjappa AS, Ponnappa KC, Nanjamma KK, Ponappa MC, Girish S, Nitin A. Sealing ability of three root-end filling materials prepared using an erbium: Yttrium aluminium garnet laser and endo sonic tip evaluated by confocal laser scanning microscopy. J Conser Dent 2015;18(4):327.

18. Shokouhinejad N, Nekoofar MH, Ashoftehyazdi K, Zahraee S, Khoshkhounejad M. Marginal adaptation of new bio ceramic materials and mineral trioxide aggregate: a scanning electron microscopy study. Iran Endod J 2014; 9: $144-8$

19. Nagesh B, Jeevani E, Sujana V, Damaraju B, Sreeha K, Ramesh P. Scanning electron microscopy (SEM) evaluation of sealing ability of MTA and EndoSequence as root-end filling materials with chitosan and carboxymethyl chitosan (CMC) as retrograde smear layer removing agents. J Conser Dent 2016;19(2):143. 